\title{
High-resolution crystal structures of ribosome-bound chloramphenicol and erythromycin provide the ultimate basis for their competition
}

\author{
MAXIM S. SVETLOV, ${ }^{1,5}$ ELENA PLESSA, ${ }^{2,5}$ CHIH-WEI CHEN, ${ }^{3}$ ANTHONY BOUGAS, ${ }^{2}$ MARIOS G. KROKIDIS, ${ }^{2}$ \\ GEORGE P. DINOS, ${ }^{2}$ and YURY S. POLIKANOV ${ }^{1,3,4}$ \\ ${ }^{1}$ Center for Biomolecular Sciences, University of Illinois at Chicago, Chicago, Illinois 60607, USA \\ ${ }^{2}$ Department of Biochemistry, School of Medicine, University of Patras, 26504 Patras, Greece \\ ${ }^{3}$ Department of Biological Sciences, University of Illinois at Chicago, Chicago, Illinois 60607, USA \\ ${ }^{4}$ Department of Medicinal Chemistry and Pharmacognosy, University of Illinois at Chicago, Chicago, Illinois 60607, USA
}

\begin{abstract}
The $70 \mathrm{~S}$ ribosome is a major target for antibacterial drugs. Two of the classical antibiotics, chloramphenicol (CHL) and erythromycin (ERY), competitively bind to adjacent but separate sites on the bacterial ribosome: the catalytic peptidyl transferase center (PTC) and the nascent polypeptide exit tunnel (NPET), respectively. The previously reported competitive binding of $\mathrm{CHL}$ and ERY might be due either to a direct collision of the two drugs on the ribosome or due to a druginduced allosteric effect. Because of the resolution limitations, the available structures of these antibiotics in complex with bacterial ribosomes do not allow us to discriminate between these two possible mechanisms. In this work, we have obtained two crystal structures of CHL and ERY in complex with the Thermus thermophilus 70S ribosome at a higher resolution (2.65 and $2.89 \AA$, respectively) allowing unambiguous placement of the drugs in the electron density maps. Our structures provide evidence of the direct collision of CHL and ERY on the ribosome, which rationalizes the observed competition between the two drugs.
\end{abstract}

Keywords: chloramphenicol; erythromycin; competition; antibiotic; 70 S ribosome; X-ray structure; inhibition of translation; peptidyl transferase center; nascent peptide exit tunnel

\section{INTRODUCTION}

Protein synthesis is a key step in the gene expression pathway, which is catalyzed by the ribosome. The ribosome is composed of two unequal subunits, small and large (30S and $50 \mathrm{~S}$ in bacteria), which join together to form a $70 \mathrm{~S}$ particle. While the $30 \mathrm{~S}$ subunit is in charge of decoding of the genetic information carried by the messenger RNA (mRNA), the peptidyl transferase center (PTC) of the $50 \mathrm{~S}$ subunit links amino acids into a nascent polypeptide which is then threaded through the nascent peptide exit tunnel (NPET) that spans the body of the large subunit. PTC and NPET are the sites targeted by the broadest array of inhibitors belonging to several distinct chemical classes, including phenicols, lincosamides, oxazolidinones, pleuromutilins, streptogramins $A$ and $B$, macrolides, and ketolides (Lin et al. 2018; Polikanov et al. 2018). Some of

\footnotetext{
${ }^{5}$ These authors contributed equally to this work.

Corresponding authors: dinosg@upatras.gr, yuryp@uic.edu

Article is online at http://www.rnajournal.org/cgi/doi/10.1261/rna. 069260.118
}

these inhibitors are among the most successful antimicrobial drugs used in the clinic to treat human bacterial infections (Van Boeckel et al. 2014).

Among the "oldest" and the best studied ribosometargeting antibiotics are chloramphenicol ( $\mathrm{CHL}$, Fig. 1A) and erythromycin (ERY, Fig. 1B), which are also the prototype representatives of their respective chemical classesphenicols and macrolides. CHL binds in the A site of the PTC and is thought to act as a competitive inhibitor, which prevents binding of an aminoacyl moiety of an incoming aminoacyl-tRNA substrate in the ribosomal A site resulting in inhibition of peptide bond formation (Hansen et al. 2003; Bulkley et al. 2010; Dunkle et al. 2010). Although the binding site of ERY (and all other macrolides) is located in the NPET $10 \AA$ away from the PTC (Tu et al. 2005; Bulkley

(C) 2019 Svetlov et al. This article is distributed exclusively by the RNA Society for the first 12 months after the full-issue publication date (see http://rnajournal.cshlp.org/site/misc/terms.xhtml). After 12 months, it is available under a Creative Commons License (Attribution-NonCommercial 4.0 International), as described at http:// creativecommons.org/licenses/by-nc/4.0/. 

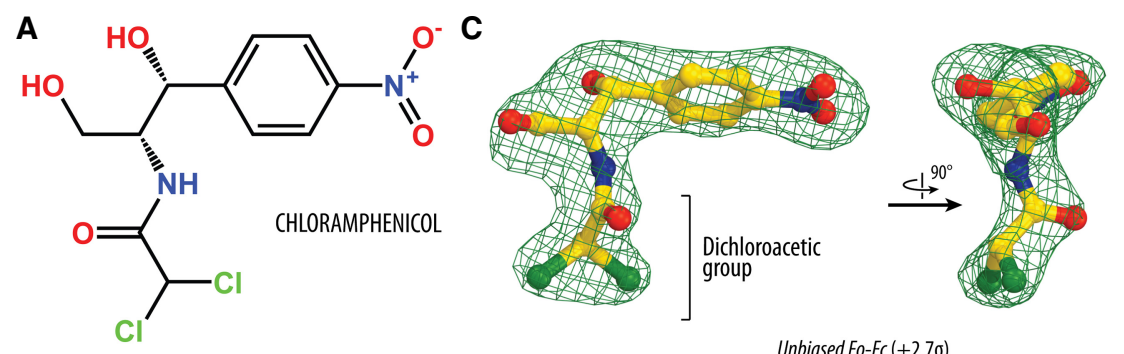

Unbiased $F o-F c(+2.7 \sigma)$
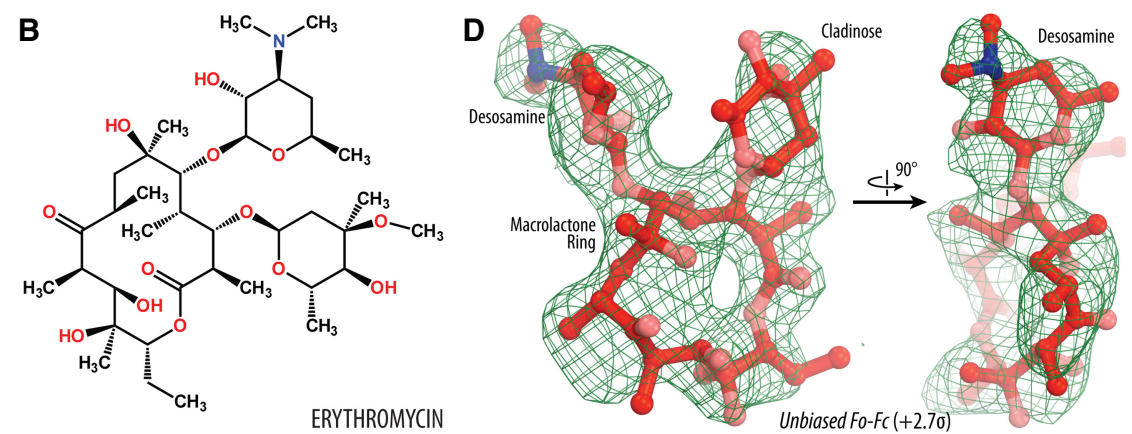

FIGURE 1. Electron density maps of ribosome-bound chloramphenicol and erythromycin. $(A, B)$ Chemical structures of PTC-targeting antibiotic chloramphenicol $(A, C H L)$ and NPETbinding macrolide erythromycin $(B, E R Y) .(C, D)$ Unbiased $F_{o}-F_{c}$ electron difference Fourier maps (green mesh) of $\mathrm{CHL}(C)$ and ERY $(D)$ in complex with the $T$. thermophilus $70 S$ ribosome viewed from two different perspectives. The refined models of CHL or ERY are displayed in their respective electron densities contoured at 2.7 $\sigma$. Carbon atoms are colored yellow for $\mathrm{CHL}$ and red for ERY; nitrogens are blue; oxygens are red for $\mathrm{CHL}$ and salmon for ERY. Key chemical moieties of each drug are labeled. tation. However, even with the overall better quality crystallographic data, neither of the newer structures allowed for the unambiguous placing of the dichloroacetic moiety of $\mathrm{CHL}$ in the electron density maps. Nevertheless, these structures did not reveal any significant drug-induced rearrangements of the 23S rRNA nucleotides surrounding the PTC and NPET that would affect binding of the competitor drug. Therefore, most likely, the observed competition between the $\mathrm{CHL}$ and ERY is due to their steric hindrance.

In this work, we have obtained two crystal structures of $\mathrm{CHL}$ and ERY in complex with the Tth $70 \mathrm{~S}$ ribosome at a higher resolution (2.65 and $2.89 \AA$, respectively) allowing unambiguous placement of the $\mathrm{CHL}$ dichloroacetic moiety and the ERY desosamine sugar. Our structures provide evidence of the direct collision of $\mathrm{CHL}$ and ERY on the ribosome, which rationalizes the observed competition between the two drugs. et al. 2010; Dunkle et al. 2010), CHL and ERY are known to compete with each other (Vazquez 1966). This competition might be due to either a direct collision of the two drugs on the ribosome or a drug-induced allosteric effect. The early $\mathrm{X}$-ray crystal structures of $\mathrm{CHL}$ and ERY in complex with the $50 S$ large ribosomal subunit from eubacterium Deinococcus radiodurans (PDB entries $1 \mathrm{~K} 01$ and $1 \mathrm{JZY}$, respectively [Schlünzen et al. 2001]) suggested that these drugs have nonoverlapping binding sites (Supplemental Fig. S1A) and, therefore, should not directly compete with each other pointing to an allosteric mechanism. Later structures by two independent groups revealed substantially different orientations of $\mathrm{CHL}$ and $\mathrm{ERY}$ in their binding sites on the ribosome (Supplemental Fig. S1B,C; Bulkley et al. 2010; Dunkle et al. 2010). These structures of $\mathrm{CHL}$ and ERY in complex with bacterial $70 \mathrm{~S}$ ribosomes from either Escherichia coli (Eco) (Dunkle et al. 2010) or Thermus thermophilus (Tth) (Bulkley et al. 2010) provided better quality maps allowing more accurate placement of the drugs in their binding sites. The structures revealed that the dichloroacetic moiety of $\mathrm{CHL}$ and the desosamine moiety of ERY, chemical groups that are crucial for binding to the ribosome, are either directly juxtaposed or potentially even overlap (Supplemental Fig. S1B,C; Bulkley et al. 2010; Dunkle et al. 2010). Whether the dichloroacetic moiety of CHL clashes with the desosamine of ERY depends on its particular orien-

\section{RESULTS AND DISCUSSION}

\section{High-resolution structures of the ribosome-bound $\mathrm{CHL}$ and ERY}

In order to unambiguously determine the exact location of all chemical moieties of $\mathrm{CHL}$ and ERY in their binding sites on the bacterial ribosome, we cocrystallized Tth $70 \mathrm{~S}$ ribosomes in the presence of mRNA, deacylated A-, $\mathrm{P}_{-}$, and $\mathrm{E}-$ site tRNAs, and either CHL or ERY and solved the structures of the obtained complexes at 2.65 and $2.89 \AA$ resolution, respectively (Supplemental Table S1). To our knowledge, these are the highest resolution structures of ribosome-bound $\mathrm{CHL}$ and ERY reported to date. Our structural data revealed more characteristic features of the drug molecules in the electron density maps (Figs. $1 C, D, 2 C, F)$. The better quality electron density maps allowed us to visualize the dichloroacetic moiety of $\mathrm{CHL}$ (Fig. 2C) and the desosamine sugar of ERY (Fig. 2F), whose placement in the previous structures was ambiguous (Fig. $2 A, B, D, E)$. We believe that the optimized experimental procedures and inclusion of mRNA and tRNAs in our ribosome complexes provided additional stabilization to the ribosome that, in turn, contributed to the higher resolution, similar to other recent structures of ribosome-bound antibiotics (Almutairi et al. 2017; Metelev et al. 2017; 

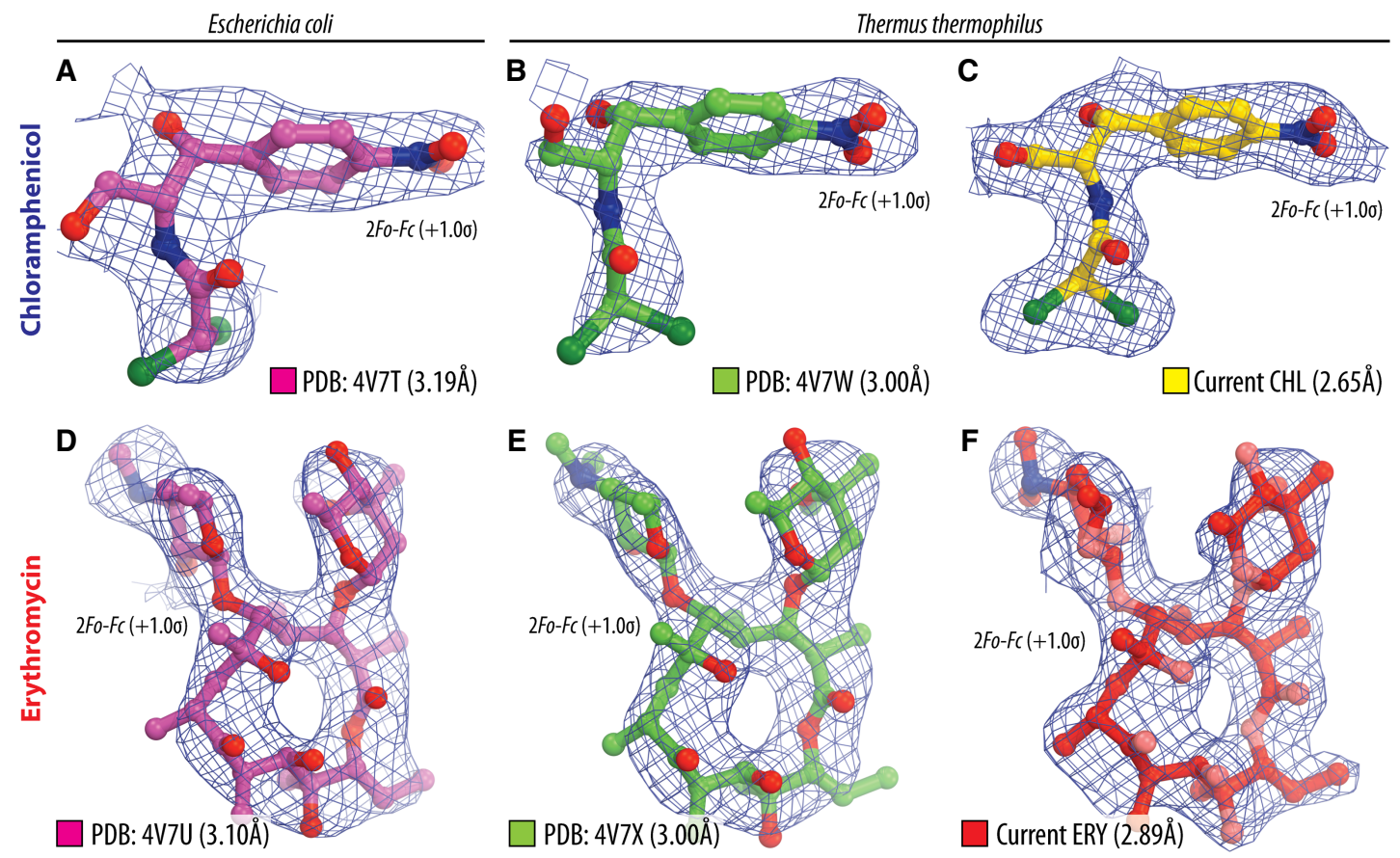

FIGURE 2. Comparison of the electron density maps of ribosome-bound $\mathrm{CHL}$ and $\mathrm{ERY}$ from different structures. The refined models of $\mathrm{CHL}$ ( $\mathrm{A}-\mathrm{C}$ ) or ERY (D-F) that were either published previously (Bulkley et al. 2010; Dunkle et al. 2010) or determined in the current study are shown in their respective $2 F_{\mathrm{o}}-F_{\mathrm{c}}$ electron density maps contoured at $1.0 \sigma$.

Osterman et al. 2017; Pantel et al. 2018; Tereshchenkov et al. 2018).

The binding position of the amphenicol moiety (but not the dichloracetic) of $\mathrm{CHL}$ molecule in our structure is identical to those observed previously for $\mathrm{CHL}$ bound to vacant $70 S$ ribosomes from Eco (Supplemental Fig. S1B,D; Dunkle et al. 2010) or Tth (Supplemental Fig. S1C,D; Bulkley et al. 2010) in the absence of mRNA and tRNAs. This suggests that the presence of the deacylated tRNAs in the $A$ and $P$ sites does not affect the general mode of $\mathrm{CHL}$ binding to the ribosome. In our structure, the oxygens of the nitro group in the $\mathrm{CHL}$ form hydrogen bonds $(\mathrm{H}-$ bonds) with the A76 ribose 3'-hydroxyl of the deacylated A-site tRNA and A76 ribose 2'-hydroxyl of the deacylated P-site tRNA (Supplemental Fig. S2). It is unclear whether such interactions are possible in the translating ribosome when the A- and P-site tRNAs are attached to the aminoacyl and peptidyl groups, respectively. Nevertheless, our structure demonstrates that the amphenicol part of $\mathrm{CHL}$ anchors it in the PTC, directing the attached dichloroacetic moiety toward the macrolide binding site in the NPET. The overall quality of the obtained electron density map allowed us to unambiguously place all atoms of the dichloracetic moiety (Figs. 1C, 2C). Although in solution this moiety has a certain degree of rotational freedom, in the structure it adopts a unique conformation due to stabilization provided by the $\mathrm{H}$-bond formed with the $\mathrm{N} 6$ atom of nucleotide $\mathrm{A} 2062$ of the $23 \mathrm{~S}$ rRNA, which rotates by $\sim 160^{\circ}$ around its $\mathrm{N}$-glycosidic bond into a position where it forms a Hoogsteen base pair with the residue $\mathrm{m}^{2} \mathrm{~A} 2503$ (Fig. 3; Supplemental Movie S1). Similar reorientation of this nucleotide was previously observed in the 70S-CHL structures with vacant Eco (Dunkle et al. 2010) or Tth (Bulkley et al. 2010) ribosomes.

In our 70S-ERY structure, the drug molecule is located in the canonical macrolide-binding pocket in the NPET near the PTC, which is identical to those observed previously for ERY bound to vacant 70S ribosomes from Eco (Supplemental Fig. S1B,E; Dunkle et al. 2010) or Tth (Supplemental Fig. S1C,E; Bulkley et al. 2010) in the absence of mRNA and tRNAs. Binding of ERY to the ribosome is largely mediated by the $\mathrm{H}$-bonding between the 23S rRNA residues A2058 and A2059 and the desosamine moiety of the drug, which is pointed in the direction of the PTC (Supplemental Movie $\mathrm{S} 1$; Fig. 4). Curiously, in our structure, ERY causes similar reorientation of the nucleotide A2062 of the 23S rRNA (Fig. $4 \mathrm{~B}, \mathrm{C}$ ) as in the case with $\mathrm{CHL}$ (Fig. 3C,D). However, unlike $\mathrm{CHL}$, which forms $\mathrm{H}$-bond with the $\mathrm{A} 2062$ base, ERY does not establish this type of interaction but instead forms van der Waals contact with the A2062/A2503 bases (Supplemental Fig. S3). Moreover, this ERY-induced conformational change of A2062 is observed consistently only in Tth $70 S$ ribosomes (current work and Bulkley et al. 2010), but not in the case with Eco $70 S$ ribosomes (Dunkle et al. 2010), or Haloarcula marismortui 50 S ribosomal subunit (Tu et al. 2005). This rearrangement potentially could represent a species-specific response to the binding of a macrolide antibiotic. 
A

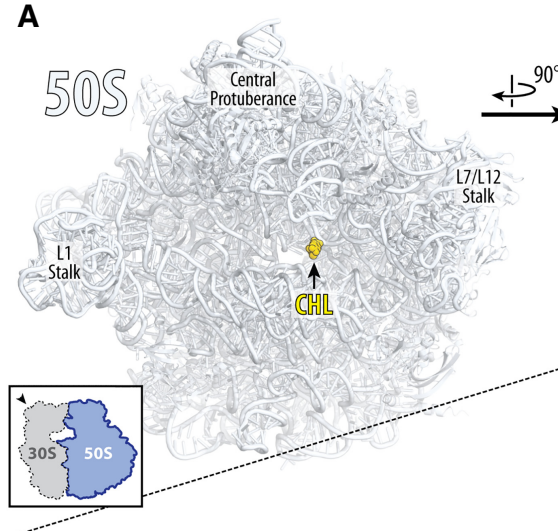

B

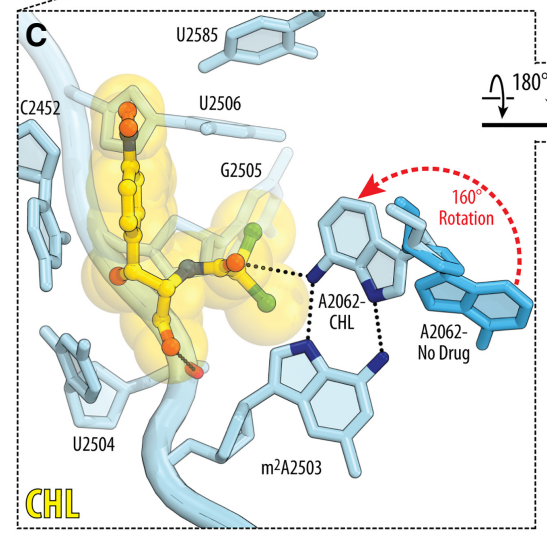

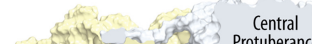
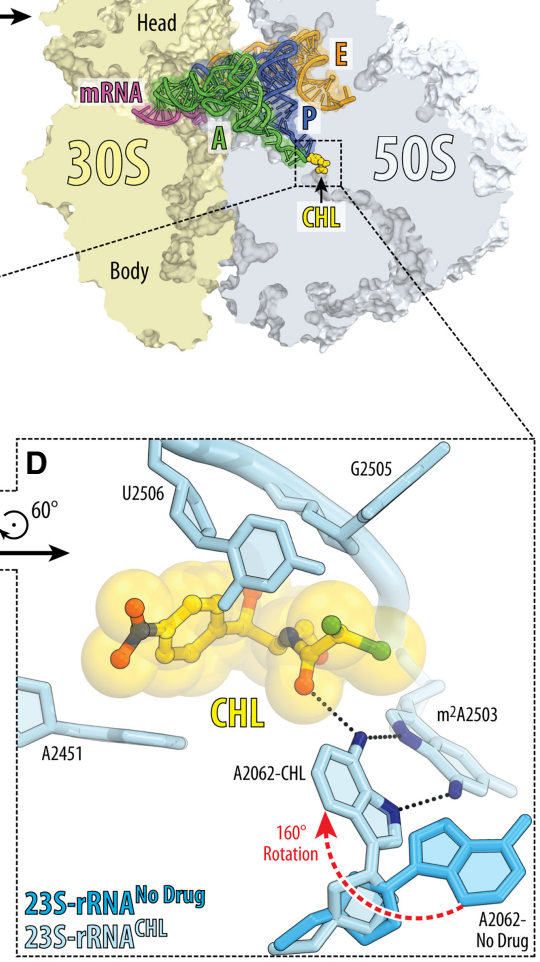

FIGURE 3. Structure of $\mathrm{CHL}$ in complex with the $70 \mathrm{~S}$ ribosome and $\mathrm{A}_{-}, \mathrm{P}-$-, and $\mathrm{E}$-site tRNAs. $(A, B)$ Overview of the $\mathrm{CHL}$ binding site (yellow) in the Tth $70 \mathrm{~S}$ ribosome viewed from the PTC down the tunnel as indicated by the inset $(A)$, or as a cross-cut section through the ribosome $(B)$. The $30 \mathrm{~S}$ subunit is shown in light yellow, the $50 \mathrm{~S}$ subunit is in light blue, the mRNA is in magenta, and the A-, $\mathrm{P}_{-}$, and E-site tRNAs are colored green, dark blue, and orange, respectively. $(C, D)$ Close-up views of the CHL bound in the PTC. The E. coli nucleotide numbering is used. Potential $\mathrm{H}$-bond interactions are indicated with dashed lines. Note that by forming an $\mathrm{H}$-bond with the base of nucleotide A2062 of the 23S rRNA (light blue) CHL causes characteristic rotation of this nucleotide by $\sim 160^{\circ}$ to form Hoogsteen base pair with the $\mathrm{m}^{2} \mathrm{~A} 2503$ of the $23 \mathrm{~S}$ rRNA (red dashed arrow). N6 and N7 atoms of nucleotides A2062 and m² A2503 are highlighted in dark blue. The unrotated conformation of A2062 observed in the absence of the drug is shown in blue (PDB entry 4Y4P [Polikanov et al. 2015]).

\section{Structural basis for competition between ERY and $\mathrm{CHL}$}

The two chemical groups of $\mathrm{CHL}$ and ERY that come into close proximity are the dichloroacetic and dimethylamine moieties. The exact rotational orientation of the dichloroacetic group of $\mathrm{CHL}$, which is crucial for our subsequent analysis, was uncertain from the previous structures (Fig. $2 A, B)$. Due to a higher resolution and overall better quality electron density maps that we observed for $\mathrm{CHL}$ and ERY (Fig. 2C,F), we were able to unambiguously determine the placement of the dichloroacetic moiety of $\mathrm{CHL}$ and provide definitive structural basis for their competition that was previously observed in biochemical assays (Wolfe and Hahn 1965; Vazquez 1966; Pestka 1974).

Superposition of our CHL and ERY structures reveals a direct steric clash between the chlorine atoms of the erance
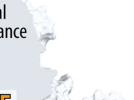

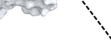

dichloroacetic moiety of $\mathrm{CHL}$ and the dimethylamine of the desosamine sugar of ERY (Fig. 5). Both chemical groups in each of the two drugs are essential for their binding to the ribosome. The dichloroacetic moiety of $\mathrm{CHL}$ forms $\mathrm{H}$-bond with the $\mathrm{N} 6$ atom of A2062 of the 23S rRNA (Fig. 5A; Supplemental Movie S1), and mutation of this base to cytidine leads to $\mathrm{CHL}$ resistance (Mankin and Garrett 1991; Kloss et al. 1999). Likewise, inability to form $\mathrm{H}$-bonds between desosamine of ERY and the N1 and N6 atoms of A2058 and A2059 bases, respectively (Fig. 5B; Supplemental Movie S1), when these bases are mutated to guanines, also causes antibiotic resistance (Vester and Garrett 1987; Sander et al. 1997; Vester and Douthwaite 2001). Therefore, even a minor displacement of any of these groups should lead to disruption of the crucial interaction for either $\mathrm{CHL}$ or ERY that would be manifested as competitive binding.

The competition between $\mathrm{CHL}$ and ERY was demonstrated biochemically decades ago using ribosomes from several bacterial species, including $E$. coli (Wolfe and Hahn 1965; Vazquez 1966; Pestka 1974). However, such competition has never been tested for the Gram-negative bacterium T. thermophilus, which we use as a source of ribosomes in our structural studies. To confirm the ability of macrolides to displace prebound $\mathrm{CHL}$ from $T$ th $70 \mathrm{~S}$ ribosomes, we used competition-binding assay exploiting $\left[{ }^{14} \mathrm{C}\right]-\mathrm{CHL}$ and nonlabeled ERY. In our assays, the macrolide efficiently displaces $\mathrm{CHL}$ from both Eco (Supplemental Fig. S4A) and Tth (Supplemental Fig. S4B) ribosomes in a concentration-dependent manner. Therefore, CHL-ERY competition occurs on Tth ribosomes and is likely to be manifested in most of the bacterial species.

Our structural analysis clearly points to a direct steric clash mechanism of competition between $\mathrm{CHL}$ and ERY, which was first observed biochemically more than five decades ago. We wonder whether there are any PTC-targeting antibiotics that do not compete (and likely can coexist) with the macrolides on the bacterial ribosome. We believe that finding such inhibitors could potentially lead to the identification of drug pairs exhibiting more efficient and possibly even synergistic antibacterial action. 
A

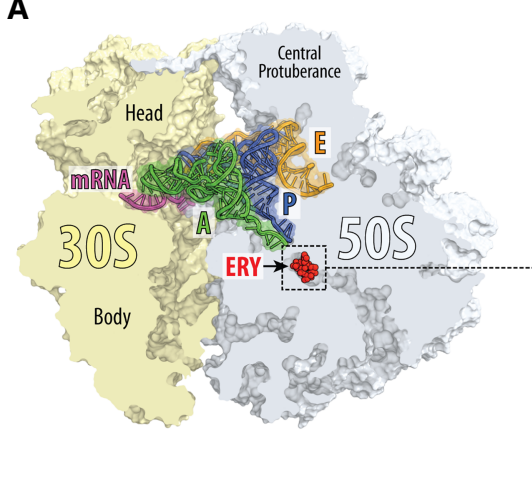

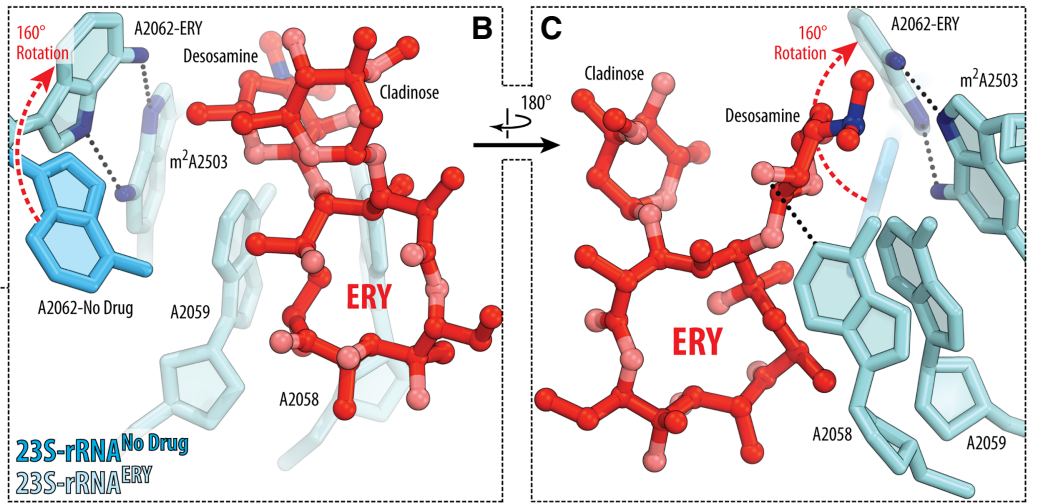

FIGURE 4. Structure of ERY in complex with the $70 S$ ribosome and A- and P-site tRNAs. (A) Overview of the ERY binding site (red) in the $T$. thermophilus $70 \mathrm{~S}$ ribosome viewed as a cross-cut through the peptide exit tunnel. The $30 \mathrm{~S}$ subunit is shown in light yellow, the $50 \mathrm{~S}$ subunit is in light blue, the mRNA is magenta, and the $A_{-}, P_{-}$, and E-site tRNAs are colored in green, dark blue, and orange, respectively. (B, $C$ ) Close-up views of the ERY binding site shown in panel $A$. Potential $\mathrm{H}$-bond interactions are indicated with dashed lines. Note that binding of ERY causes the same characteristic rotation of the nucleotide A2062 to form Hoogsteen base pair with the nucleotide $\mathrm{m}^{2} \mathrm{~A} 2503$ as observed in the case of $\mathrm{CHL}$ (red dashed arrow).

\section{MATERIALS AND METHODS}

\section{Materials for biochemical experiments}

Nonlabeled $\mathrm{CHL}$ and ERY were obtained from MilliporeSigma. Radioactively labeled $\left[{ }^{14} \mathrm{C}\right]-\mathrm{ERY}$ and $\left[{ }^{14} \mathrm{C}\right]-\mathrm{CHL}$ were obtained from MP Biomedicals and Moravek Biochemicals, respectively. Cellulose nitrate filters (type HA, 24-mm diameter, 0.45- $\mu \mathrm{m}$ pore size) were obtained from MilliporeSigma. Scintillation liquid was obtained from Bio-Rad.

\section{Biochemical preparations}

Reassociated Escherichia coli 70 S ribosomes were prepared from K12 strain as previously described (Blaha et al. 2000). Purified ribosomes were stored in a buffer containing $20 \mathrm{mM} \mathrm{HEPES-KOH}(\mathrm{pH}$ 7.6), $50 \mathrm{mM} \mathrm{CH} \mathrm{COONH}_{4}, 6 \mathrm{mM} \mathrm{Mg}$ $\left(\mathrm{CH}_{3} \mathrm{COO}\right)_{2}$, and $4 \mathrm{mM} \beta$-mercaptoethanol. $70 S$ ribosomes were prepared from Thermus thermophilus strain HB8 as described in Polikanov et al. (2014).

\section{Competition-binding assays}

Reassociated Escherichia coli 70S ribosomes $(0.2 \mu \mathrm{M}$ final concentration) were incubated in buffer A [20 mM HEPES-KOH [pH 7.6], $150 \mathrm{mM} \mathrm{NH}_{4}\left(\mathrm{CH}_{3} \mathrm{COO}\right), 6 \mathrm{mM}$ $\mathrm{Mg}\left(\mathrm{CH}_{3} \mathrm{COO}\right)_{2}, 2 \mathrm{mM}$ spermidine, 0.05 $\mathrm{mM}$ spermine, and $4 \mathrm{mM} \beta$-mercaptoethanol] with $\left[{ }^{14} \mathrm{C}\right]-\mathrm{CHL}(150 \mathrm{dpm} / \mathrm{pmol})$ at the appropriate/indicated concentration. After incubation for $10 \mathrm{~min}$ at $37^{\circ} \mathrm{C}$, the mixture was diluted with $3 \mathrm{~mL}$ of cold buffer $A$ and filtered through a $25-\mathrm{mm}$ diameter $0.45-\mu \mathrm{m}$ pore size nitrocellulose membrane (MilliporeSigma). The filter was immediately washed three times with to the $70 \mathrm{~S}$ ribosome.
$3 \mathrm{~mL}$ of cold buffer $\mathrm{A}$ and bound radioactivity was measured. Next, binding of $\left[{ }^{14} \mathrm{C}\right]-\mathrm{CHL}$ was studied in competition with nonradiolabeled $\mathrm{CHL}$ or ERY by maintaining a constant concentration of $\left[{ }^{14} \mathrm{C}\right]-\mathrm{CHL}(0.6 \mu \mathrm{M})$ and increasing concentrations of a nonradioactive competitor (Karahalios et al. 2006).

In the case of Thermus thermophilus 705 ribosomes, the binding competition between $\mathrm{CHL}$ and ERY was assessed in the same conditions as the "fragment reaction" described previously (Fernandez-Munoz et al. 1971). Each $25-\mu \mathrm{L}$ reaction contained $33 \%(\mathrm{v} / \mathrm{v})$ ethanol, $33 \mathrm{mM}$ Tris- $\mathrm{HCl} \mathrm{pH} \mathrm{7.5,} 270 \mathrm{mM} \mathrm{KCl}, 13 \mathrm{mM}$ $\mathrm{Mg}\left(\mathrm{CH}_{3} \mathrm{COO}\right)_{2}, 4 \mu \mathrm{M}$ of $T$ th $70 \mathrm{~S}$ ribosomes and $3 \mu \mathrm{M}$ of $\left[{ }^{14} \mathrm{C}\right]-$ $\mathrm{CHL}$ (150 dpm/pmol). Increasing concentrations of nonradioactive $\mathrm{CHL}$ or $\mathrm{ERY}$ were added to the reactions. After incubation at $0^{\circ} \mathrm{C}$ for $30 \mathrm{~min}$, the ribosomes were precipitated by centrifugation at $14,000 \mathrm{~g}$ for $20 \mathrm{~min}$ and radioactivity of $\mathrm{CHL}$ in ribosome-free supernatants was measured.

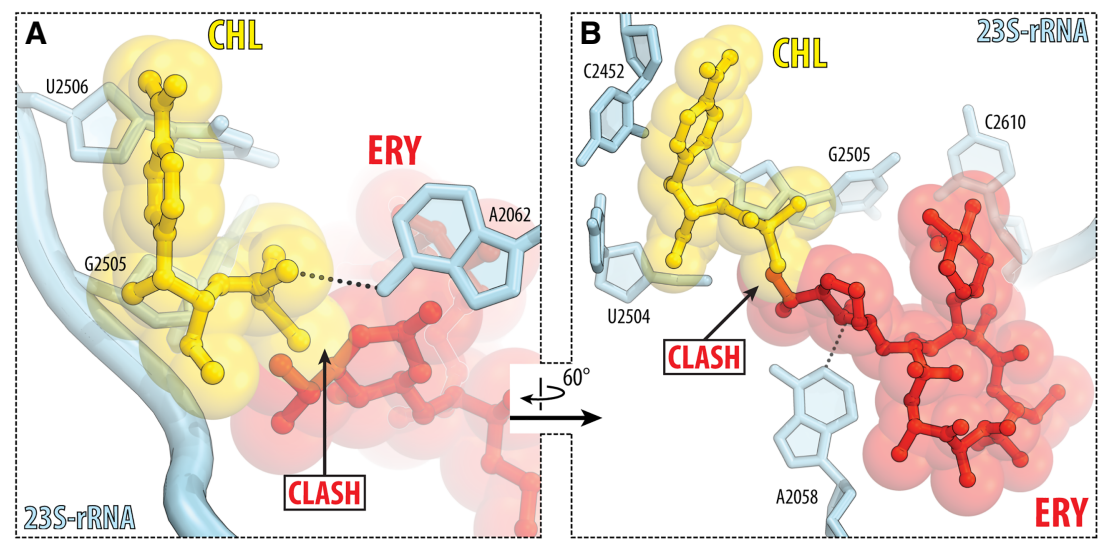

FIGURE 5. Overlap between CHL and ERY binding sites in the 70S ribosome. $(A, B)$ Two closeup views of the superimposed binding sites for $\mathrm{CHL}$ and ERY. The structures were aligned based on the domain $\mathrm{V}$ of the 23S rRNA. The coloring of the $23 \mathrm{~S}$ rRNA and the antibiotics is the same as in Figures 3 and 4. Note that dichloroacetic group of CHL clashes with the dimethylamine group of the desosamine sugar of ERY, rationalizing their mutually exclusive binding 


\section{Crystallographic structure determination}

Ribosome complexes with mRNA and tRNAs were formed as described previously (Polikanov et al. 2015). CHL or ERY were added to the preformed ribosome complexes to a final concentration of $250 \mu \mathrm{M}$ prior to crystallization. All Tth $70 \mathrm{~S}$ ribosome complexes were formed in the buffer containing $5 \mathrm{mM}$ HEPES- $\mathrm{KOH}(\mathrm{pH}$ 7.6), $50 \mathrm{mM} \mathrm{KCl}, 10 \mathrm{mM} \mathrm{NH}_{4} \mathrm{Cl}$, and $10 \mathrm{mM} \mathrm{Mg}\left(\mathrm{CH}_{3} \mathrm{COO}\right)_{2}$, and then crystallized in the buffer containing $100 \mathrm{mM}$ Tris- $\mathrm{HCl}$ (pH 7.6), 2.9\% (w/v) PEG-20 K, 7\%-12\% (v/v) MPD, 100-200 mM arginine, $0.5 \mathrm{mM} \beta$-mercaptoethanol. Crystals were grown by the vapor diffusion method in sitting drops at $19^{\circ} \mathrm{C}$ and stabilized as described previously (Polikanov et al. 2015) with CHL or ERY being added to the stabilization buffers ( $100 \mu \mathrm{M}$ each). Diffraction data were collected using beamline 24ID-C and 24ID-E at the Advanced Photon Source (Argonne National Laboratory). A complete data set for each ribosome complex was collected using $0.979 \AA$ wavelength at $100 \mathrm{~K}$ from multiple regions of the same crystal using $0.3^{\circ}$ oscillations. The raw data were integrated and scaled using the XDS software package (Kabsch 2010). All crystals belonged to the primitive orthorhombic space group $P 2{ }_{1} 2{ }_{1} 2{ }_{1}$ with approximate unit cell dimensions of $210 \times 450 \times 620 \AA$ and contained two copies of the 705 ribosome per asymmetric unit. Each structure was solved by molecular replacement using PHASER from the CCP4 program suite (McCoy et al. 2007). The search model was generated from the previously published structures of $T$. thermophilus $70 \mathrm{~S}$ ribosome with bound mRNA and tRNAs (PDB entry 4Y4P from Polikanov et al. [2015]). The initial molecular replacement solutions were refined by rigid body refinement with the ribosome split into multiple domains, followed by positional and individual B-factor refinement using PHENIX (Adams et al. 2010). Noncrystallographic symmetry restraints were applied to four domains of the $30 \mathrm{~S}$ ribosomal subunit (head, body, spur, helix 44), and four domains of the $50 \mathrm{~S}$ subunit (body, L1-stalk, L10-stalk, C terminus of the L9 protein).

Atomic models of $\mathrm{CHL}$ and ERY were generated from their known chemical structures (Fig. 1A,B) using PRODRG online software (Schüttelkopf and van Aalten 2004), which was also used to generate restraints for energy minimization and refinement based on idealized 3D geometry. Atomic models and restraints were used to fit/refine $\mathrm{CHL}$ and ERY into the obtained electron density maps (Fig. 1C,D). The final models of the Tth $70 \mathrm{~S}$ ribosome in complex with mRNA/tRNAs and CHL or ERY were generated by multiple rounds of model building in COOT (Emsley and Cowtan 2004), followed by refinement in PHENIX (Adams et al. 2010). The statistics of data collection and refinement are compiled in Supplemental Table S1. All figures showing atomic models were generated using the PyMol software (www.pymol.org).

\section{DATA DEPOSITION}

Coordinates and structure factors were deposited in the RCSB Protein Data Bank with the following accession codes: 6ND5 for the T. thermophilus 705 ribosome in complex with chloramphenicol, mRNA, A-, $\mathrm{P}-$, and E-site tRNAs; 6ND6 for the T. thermophilus 70S ribosome in complex with erythromycin, mRNA, A-, $\mathrm{P}-$, and E-site tRNAs.

\section{SUPPLEMENTAL MATERIAL}

Supplemental material is available for this article.

\section{ACKNOWLEDGMENTS}

We thank all members of the G.P.D. and Y.S.P. laboratories for valuable suggestions. We thank Drs. Alexander Mankin and Nora Vazquez-Laslop for important discussions and critical feedback. We thank the staff at NE-CAT beamlines 24ID-C and 24ID-E for help with data collection and freezing of the crystals, especially Drs. Kanagalakhatta Rajashankar, Malcolm Capel, Frank Murphy, Igor Kourinov, Anthony Lynch, Surajit Banerjee, David Neau, Jonathan Schuermann, Narayanasami Sukumar, James Withrow, Kay Perry, and Cyndi Salbego. This work is based upon research conducted at the Northeastern Collaborative Access Team beamlines, which are funded by the National Institute of General Medical Sciences from the National Institutes of Health (P41 GM103403 to NE-CAT). The Pilatus 6M detector on 24ID-C beamline is funded by a NIH-ORIP HEI (S10 RR029205 to NE-CAT). The Eiger 16M detector on 24ID-E beamline is funded by a NIH-ORIP HEl grant (S10 OD021527 to NE-CAT). This research used resources of the Advanced Photon Source, a U.S. Department of Energy (DOE) Office of Science User Facility operated for the DOE Office of Science by Argonne National Laboratory under contract no. DE-AC02-06CH11357. This work was supported by Illinois State startup funds (to Y.S.P.) and National Institutes of Health (R21-Al137584 to Y.S.P.); and University of Patras funds (to G.P.D.).

Author contributions: M.S.S. performed competition-binding assays using T. thermophilus $70 S$ ribosomes; E.P., A.B., and M. G.K. performed competition-binding assays using E. coli $70 S$ ribosomes; Y.S.P., M.S.S., and C.W.C. designed and performed X-ray crystallography experiments; G.P.D. and Y.S.P. supervised the experiments. All authors interpreted the results. M.S.S., G.P. D., and Y.S.P. wrote the manuscript.

Received October 16, 2018; accepted January 28, 2019.

\section{REFERENCES}

Adams PD, Afonine PV, Bunkóczi G, Chen VB, Davis IW, Echols N, Headd JJ, Hung LW, Kapral GJ, Grosse-Kunstleve RW, et al. 2010. PHENIX: a comprehensive Python-based system for macromolecular structure solution. Acta Crystallogr D Biol Crystallogr 66: 213-221. doi:10.1107/S0907444909052925

Almutairi MM, Svetlov MS, Hansen DA, Khabibullina NF, Klepacki D, Kang HY, Sherman DH, Vázquez-Laslop N, Polikanov YS, Mankin AS. 2017. Co-produced natural ketolides methymycin and pikromycin inhibit bacterial growth by preventing synthesis of a limited number of proteins. Nucleic Acids Res 45: 95739582. doi:10.1093/nar/gkx673

Blaha G, StelzI U, Spahn CM, Agrawal RK, Frank J, Nierhaus KH. 2000. Preparation of functional ribosomal complexes and effect of buffer conditions on tRNA positions observed by cryoelectron microscopy. Methods Enzymo/ 317: 292-309. doi:10.1016/S0076-6879(00) 17021-1

Bulkley D, Innis CA, Blaha G, Steitz TA. 2010. Revisiting the structures of several antibiotics bound to the bacterial ribosome. Proc Natl Acad Sci 107: 17158-17163. doi:10.1073/pnas .1008685107

Dunkle JA, Xiong L, Mankin AS, Cate JH. 2010. Structures of the Escherichia coli ribosome with antibiotics bound near the peptidyl transferase center explain spectra of drug action. Proc Natl Acad Sci 107: 17152-17157. doi:10.1073/pnas. 1007988107 
Emsley P, Cowtan K. 2004. Coot: model-building tools for molecular graphics. Acta Crystallogr D Biol Crystallogr 60: 2126-2132. doi:10.1107/S0907444904019158

Fernandez-Munoz R, Monro RE, Torres-Pinedo R, Vazquez D. 1971. Substrate- and antibiotic-binding sites at the peptidyl-transferase centre of Escherichia coli ribosomes. Studies on the chloramphenicol, lincomycin and erythromycin sites. Eur J Biochem 23: 185193. doi:10.1111/j.1432-1033.1971.tb01607.x

Hansen JL, Moore PB, Steitz TA. 2003. Structures of five antibiotics bound at the peptidyl transferase center of the large ribosomal subunit. J Mol Biol 330: 1061-1075. doi:10.1016/S0022-2836 (03)00668-5

Kabsch W. 2010. Xds. Acta Crystallogr D Biol Crystallogr 66: 125-132. doi:10.1107/S0907444909047337

Karahalios P, Kalpaxis DL, Fu H, Katz L, Wilson DN, Dinos GP. 2006. On the mechanism of action of 9-O-arylalkyloxime derivatives of 6-O-mycaminosyltylonolide, a new class of 16-membered macrolide antibiotics. Mol Pharmacol 70: 1271-1280. doi:10.1124/mol .106 .026567

Kloss P, Xiong L, Shinabarger DL, Mankin AS. 1999. Resistance mutations in 23S rRNA identify the site of action of the protein synthesis inhibitor linezolid in the ribosomal peptidyl transferase center. $J$ Mol Biol 294: 93-101. doi:10.1006/jmbi.1999.3247

Lin J, Zhou D, Steitz TA, Polikanov YS, Gagnon MG. 2018. Ribosometargeting antibiotics: modes of action, mechanisms of resistance, and implications for drug design. Annu Rev Biochem 87: 451478. doi:10.1146/annurev-biochem-062917-011942

Mankin AS, Garrett RA. 1991. Chloramphenicol resistance mutations in the single 23S rRNA gene of the archaeon Halobacterium halobium. J Bacteriol 173: 3559-3563. doi:10.1128/jb.173.11 .3559-3563.1991

McCoy AJ, Grosse-Kunstleve RW, Adams PD, Winn MD, Storoni LC, Read RJ. 2007. Phaser crystallographic software. J Appl Crystallogr 40: 658-674. doi:10.1107/S0021889807021206

Metelev M, Osterman IA, Ghilarov D, Khabibullina NF, Yakimov A, Shabalin K, Utkina I, Travin DY, Komarova ES, Serebryakova M, et al. 2017. Klebsazolicin inhibits 70 S ribosome by obstructing the peptide exit tunnel. Nat Chem Biol 13: 1129-1136. doi:10 .1038/nchembio.2462

Osterman IA, Khabibullina NF, Komarova ES, Kasatsky P, Kartsev VG, Bogdanov AA, Dontsova OA, Konevega AL, Sergiev PV, Polikanov YS. 2017. Madumycin II inhibits peptide bond formation by forcing the peptidyl transferase center into an inactive state. Nucleic Acids Res 45: 7507-7514. doi:10.1093/nar/gkx413

Pantel L, Florin T, Dobosz-Bartoszek M, Racine E, Sarciaux M, Serri M, Houard J, Campagne JM, de Figueiredo RM, Midrier C, et al. 2018. Odilorhabdins, antibacterial agents that cause miscoding by binding at a new ribosomal site. Mol Cell 70: 83-94. doi:10 .1016/j.molcel.2018.03.001

Pestka S. 1974. Antibiotics as probes of ribosome structure: binding of chloramphenicol and erythromycin to polyribosomes; effect of other antibiotics. Antimicrob Agents Chemother 5: 255-267. doi:10.1128/AAC.5.3.255

Polikanov YS, Steitz TA, Innis CA. 2014. A proton wire to couple aminoacyl-tRNA accommodation and peptide-bond formation on the ribosome. Nat Struct Mol Biol 21: 787-793. doi:10.1038/nsmb .2871

Polikanov YS, Melnikov SV, Söll D, Steitz TA. 2015. Structural insights into the role of rRNA modifications in protein synthesis and ribosome assembly. Nat Struct Mol Biol 22: 342-344. doi:10.1038/ nsmb.2992

Polikanov YS, Aleksashin NA, Beckert B, Wilson DN. 2018. The mechanisms of action of ribosome-targeting peptide antibiotics. Front Mol Biosci 5: 48. doi:10.3389/fmolb.2018.00048

Sander P, Prammananan T, Meier A, Frischkorn K, Böttger EC. 1997. The role of ribosomal RNAs in macrolide resistance. Mol Microbiol 26: 469-480. doi:10.1046/j.1365-2958.1997.5811946.x

Schlünzen F, Zarivach R, Harms J, Bashan A, Tocilj A, Albrecht R, Yonath A, Franceschi F. 2001. Structural basis for the interaction of antibiotics with the peptidyl transferase centre in eubacteria. Nature 413: 814-821. doi:10.1038/35101544

Schüttelkopf AW, van Aalten DM. 2004. PRODRG: a tool for highthroughput crystallography of protein-ligand complexes. Acta Crystallogr D Biol Crystallogr 60: 1355-1363. doi:10.1107/ S0907444904011679

Tereshchenkov AG, Dobosz-Bartoszek M, Osterman IA, Marks J, Sergeeva VA, Kasatsky P, Komarova ES, Stavrianidi AN, Rodin IA, Konevega AL, et al. 2018. Binding and action of amino acid analogs of chloramphenicol upon the bacterial ribosome. $J$ Mol Biol 430: 842-852. doi:10.1016/j.jmb.2018.01.016

Tu D, Blaha G, Moore PB, Steitz TA. 2005. Structures of MLSBK antibiotics bound to mutated large ribosomal subunits provide a structural explanation for resistance. Cell 121: 257-270. doi:10.1016/j .cell.2005.02.005

Van Boeckel TP, Gandra S, Ashok A, Caudron Q, Grenfell BT, Levin SA, Laxminarayan R. 2014. Global antibiotic consumption 2000 to 2010: an analysis of national pharmaceutical sales data. Lancet Infect Dis 14: 742-750. doi:10.1016/S1473-3099(14) 70780-7

Vazquez D. 1966. Binding of chloramphenicol to ribosomes. The effect of a number of antibiotics. Biochim Biophys Acta 114: 277288. doi:10.1016/0005-2787(66)90309-1

Vester B, Douthwaite S. 2001. Macrolide resistance conferred by base substitutions in 23S rRNA. Antimicrob Agents Chemother 45: 112. doi:10.1128/AAC.45.1.1-12.2001

Vester B, Garrett RA. 1987. A plasmid-coded and site-directed mutation in Escherichia coli 23S RNA that confers resistance to erythromycin: implications for the mechanism of action of erythromycin. Biochimie 69: 891-900. doi:10.1016/0300-9084(87)90217-3

Wolfe AD, Hahn FE. 1965. Mode of action of chloramphenicol. IX. Effects of chloramphenicol upon a ribosomal amino acid polymerization system and its binding to bacterial ribosome. Biochim Biophys Acta 95: 146-155. doi:10.1016/0005-2787(65)90219-4 

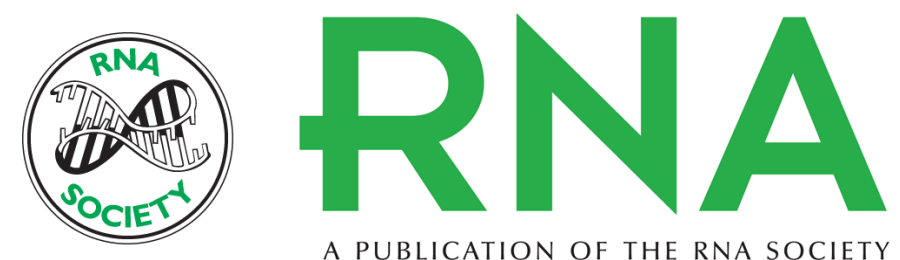

A PUBLICATION OF THE RNA SOCIETY

\title{
High-resolution crystal structures of ribosome-bound chloramphenicol and erythromycin provide the ultimate basis for their competition
}

\author{
Maxim S. Svetlov, Elena Plessa, Chih-Wei Chen, et al.
}

RNA 2019 25: 600-606 originally published online February 7, 2019

Access the most recent version at doi:10.1261/rna.069260.118

\section{Supplemental} Material

References

Creative Commons License

Email Alerting Service
http://rnajournal.cshlp.org/content/suppl/2019/02/07/rna.069260.118.DC1

This article cites 31 articles, 6 of which can be accessed free at: http://rnajournal.cshlp.org/content/25/5/600.full.html\#ref-list-1

This article is distributed exclusively by the RNA Society for the first 12 months after the full-issue publication date (see http://rnajournal.cshlp.org/site/misc/terms.xhtml). After 12 months, it is available under a Creative Commons License (Attribution-NonCommercial 4.0 International), as described at http://creativecommons.org/licenses/by-nc/4.0/.

Receive free email alerts when new articles cite this article - sign up in the box at the top right corner of the article or click here.

\section{|||||||| Providing Precise Solutions for your research.}

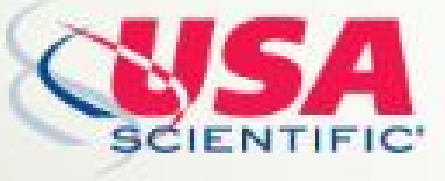

To subscribe to $R N A$ go to:

http://rnajournal.cshlp.org/subscriptions 